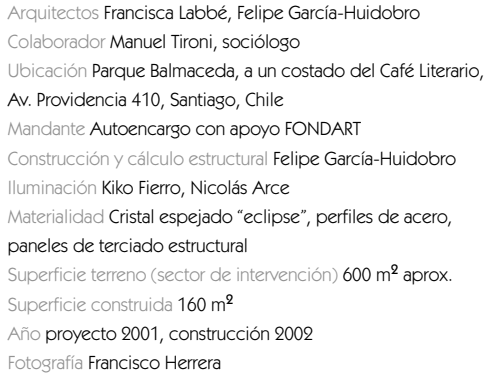

Un montaje urbano de carácter transitorio El proyecto, soporte escénico para un espectáculo de danza, propone un espacio delimitado por una estructura metálica y paredes espejadas de cristal eclipse. Este cubo - escenario contiene cuatro habitáculos del mismo material, donde se encuentran las bailarinas al empezar el espectáculo. Ellas representan el paso del tiempo, encarnando así las diferentes etapas de la vida de una mujer: la niñez, la adolescencia, la madurez y la vejez, y realizan una reflexión intimista en torno a su cuerpo. La visión que se obtiene de cada cubo y la bailarina, de su acción e interacción, varía según la posición en que se sitúe el espectador, que puede moverse libremente alrededor de los habitáculos. Así la obra genera una invitación a participar y formar parte de esta experiencia, donde el público es al mismo tiempo observado por las personas que transitan por el parque alrededor del proyecto. La danza por su parte asume un protagonismo estrechamente ligado a la arquitectura, al soporte urbano y a los efectos que se buscan producir a través del espacio irreal que crean los espejos: las bailarinas se mueven explorando un espacio que se transforma en un infinito, provocado por la sucesión de reflejos conseguida por los vidrios espejos y la iluminación escogida.

El trasfondo urbano (calles, arquitectura, tráfico, parque) se introduce en la coreografía formando una escenografía móvil y cambiante. Así la ciudad forma parte de este juego donde las luces y la música hacen del fin del montaje una fiesta, en la cual el espectador es actor de este final abierto.

\section{Francisca Labbé}

Arquitecto, Universidad Finis Terrae, 2001. Directora del proyecto Mirror, el cual fue seleccionado por el FONDART para su financiamiento. Ha trabajado en la oficina de Gestión, Diseño y Comunicación Gazi Garib + Asociados, y ha participado como investigadora y colaboradora en GENERACIÓN, proyecto multimedia de orientación vocacional dirigido a jóvenes.

\section{Felipe García Huidobro}

. Manuel Moreno Arqtos. y de Felipe Sáez.
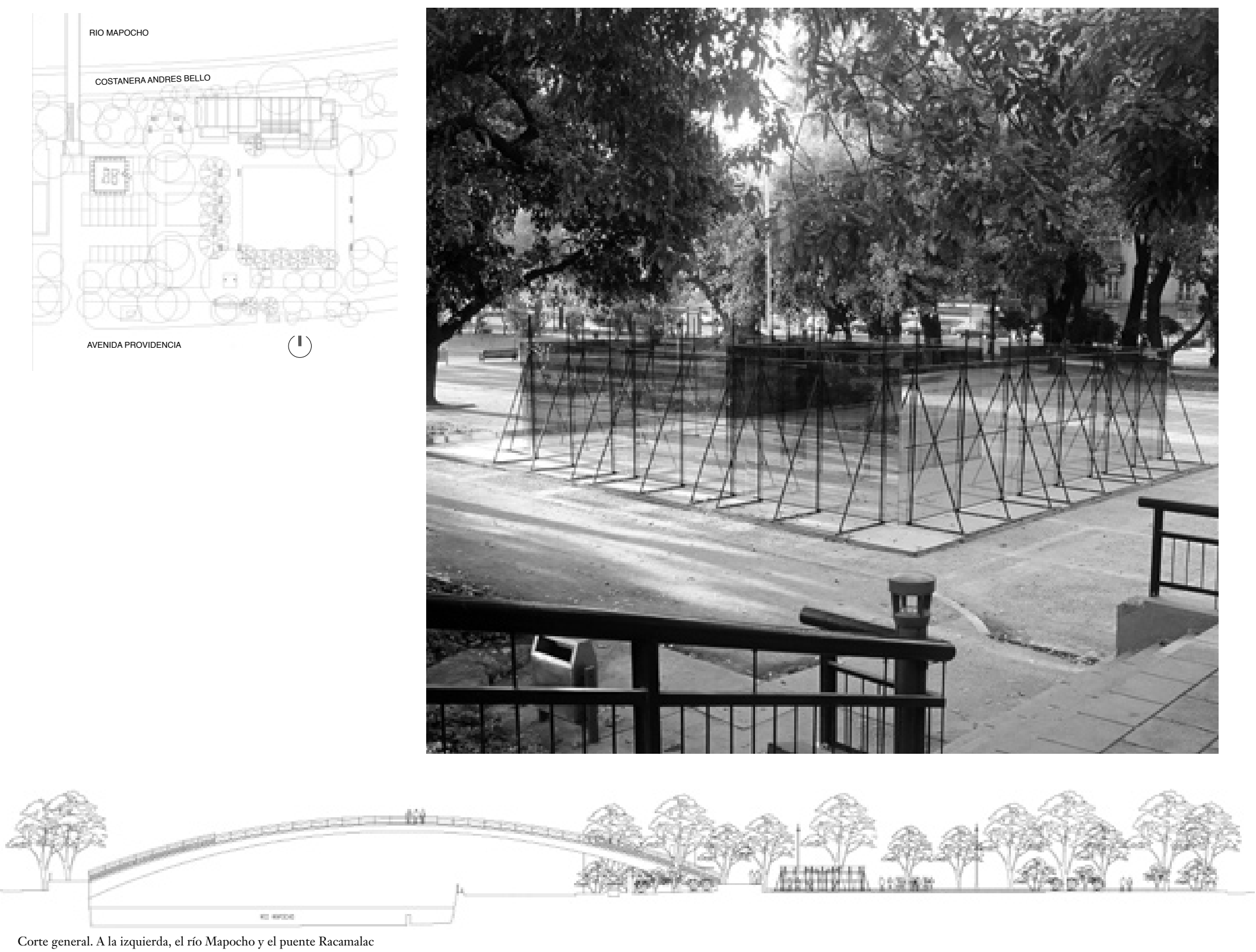

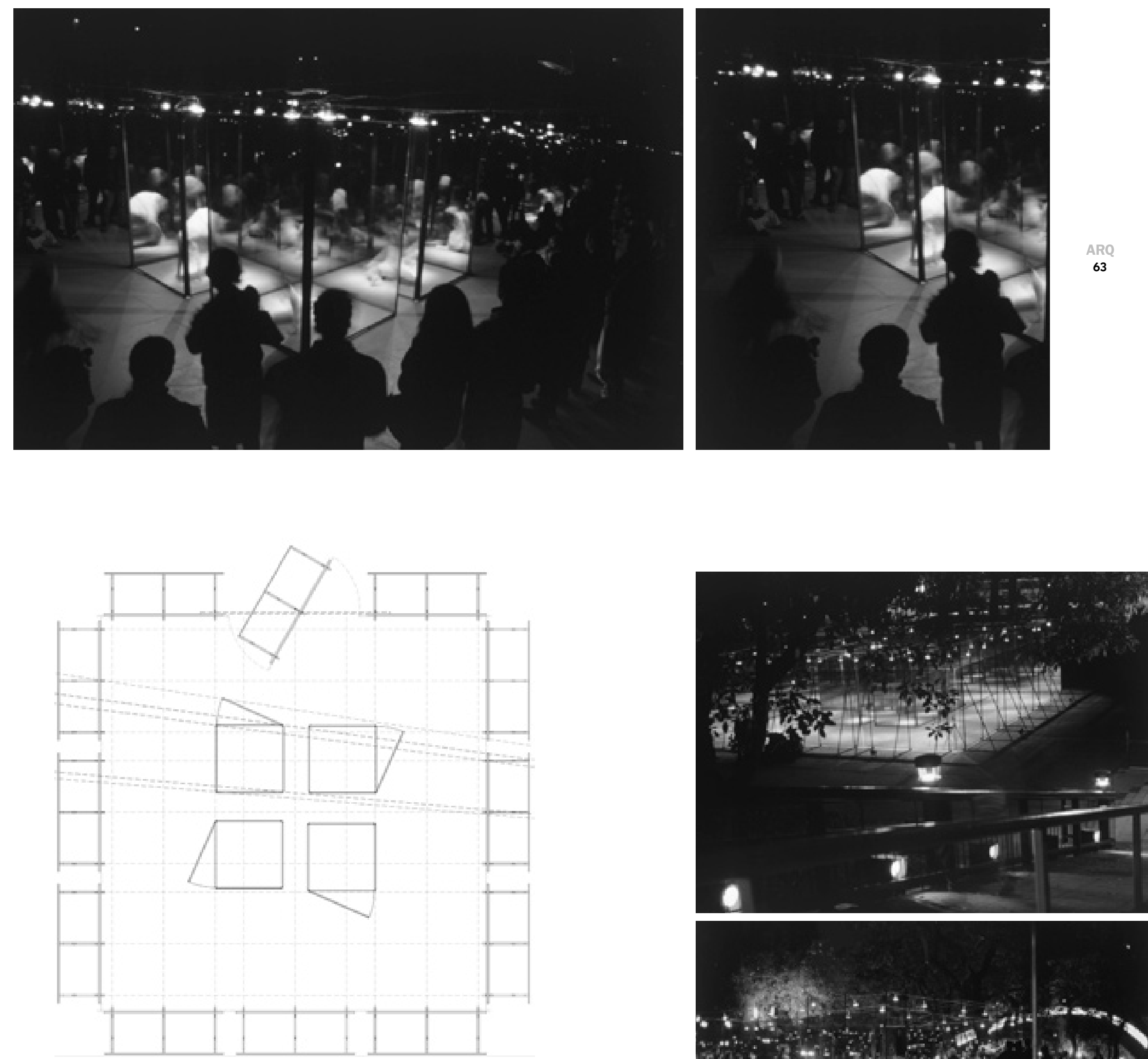

Planta del soporte escénico
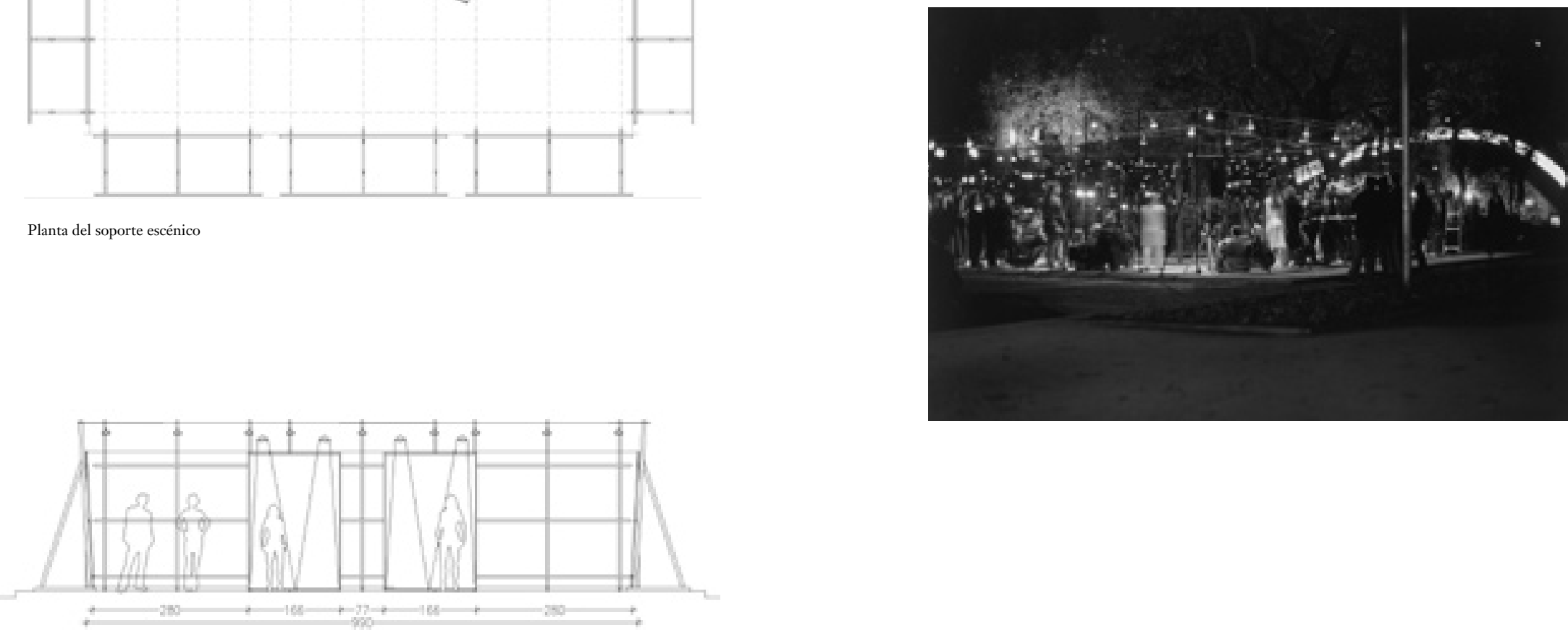